\title{
Observations and Numerical Simulations of Inertia-Gravity Waves and Shearing Instabilities in the Vicinity of a Jet Stream
}

\author{
TODD P. LANE \\ National Center for Atmospheric Research, * Boulder, Colorado \\ JAMES D. DOYLE \\ Naval Research Laboratory, Monterey, California \\ Riwal Plougonven \\ National Center for Atmospheric Research,* Boulder, Colorado \\ Melvyn A. SHAPIRo \\ National Oceanic and Atmospheric Administration, Boulder, Colorado \\ Robert D. SHARMAN \\ National Center for Atmospheric Research,* Boulder, Colorado
}

(Manuscript received 16 February 2004, in final form 2 June 2004)

\section{ABSTRACT}

\begin{abstract}
The characteristics and dynamics of inertia-gravity waves generated in the vicinity of an intense jet stream/ upper-level frontal system on 18 February 2001 are investigated using observations from the NOAA GulfstreamIV research aircraft and numerical simulations. Aircraft dropsonde observations and numerical simulations elucidate the detailed mesoscale structure of this system, including its associated inertia-gravity waves and clearair turbulence. Results from a multiply nested numerical model show inertia-gravity wave development above the developing jet/front system. These inertia-gravity waves propagate through the highly sheared flow above the jet stream, perturb the background wind shear and stability, and create bands of reduced and increased Richardson numbers. These bands of reduced Richardson numbers are regions of likely Kelvin-Helmholtz instability and a possible source of the clear-air turbulence that was observed.
\end{abstract}

\section{Introduction}

Gravity waves are ubiquitous in the atmosphere and represent a significant process within the momentum budget of the middle atmosphere (see, e.g., Fritts and Alexander 2003). Gravity waves can be generated by mountains, convection, and baroclinic waves. Component structures that exist within baroclinic waves, such as jets and upper-level fronts, are important sources of gravity waves and lower-frequency inertia-gravity waves. Upper-level fronts have also been identified as

* The National Center for Atmospheric Research is sponsored by the National Science Foundation.

Corresponding author address: Todd Lane, NCAR, P.O. Box 3000, Boulder, CO 80307-3000.

E-mail: lane@ucar.edu a preferred location for clear-air turbulence (CAT) (e.g., Kennedy and Shapiro 1980). CAT remains a serious concern for the aviation industry, and can also affect the mixing and stratosphere-troposphere exchange of chemical constituents (e.g., Shapiro 1980; Pavelin et al. 2002). The relationship between upper-level fronts and CAT has mostly been attributed to Kelvin-Helmholtz instabilities related to frontogenesis or flow deformation (e.g., Keller 1990). Also, frontally forced gravity waves have been identified as a possible source of CAT (e.g., Mancuso and Endlich 1966; Knox 1997); however, limited progress has been made in validating this hypothesis. This study investigates the generation of inertiagravity waves by a jet stream/upper-level front, and the causal relationship between the inertia-gravity waves and CAT.

Previous studies have investigated the generation of inertia-gravity waves within idealized fronts (e.g., Sny- 
der et al. 1993; Griffiths and Reeder 1996), simple baroclinic waves (e.g., O'Sullivan and Dunkerton 1995; Zhang 2004), or through observations near jets (e.g., Guest et al. 2000; Plougonven et al. 2003). Also, there have been a number of real case studies (e.g., Powers and Reed 1993; Zhang et al. 2001) focusing on the role of tropospheric inertia-gravity waves in contributing to the organization of convection and affecting weather. The waves in the aforementioned studies possessed a variety of scales, ranging from horizontal wavelengths of $O(100 \mathrm{~km})$ (mesoscale inertia-gravity waves), upward of $O(1000 \mathrm{~km})$.

Inertia-gravity waves have been observed/simulated in all regions of baroclinic waves, but most of the previous studies have identified regions within the baroclinic wave that were preferable for the formation of inertia-gravity waves. For example, using observations Guest et al. (2000) showed that the region between an upstream trough and downstream ridge is a likely region for inertia-gravity waves in the lower stratosphere. This region was also the focus of Zhang's (2004) simulations of an idealized baroclinic wave. O'Sullivan and Dunkerton's (1995) simulation, however, highlighted inertiagravity waves generated in the jet streak flow between an upstream ridge and downstream trough. Nonetheless, although these preferred regions of wave activity have been identified, the existence of waves in other parts of the baroclinic wave is not unlikely. The case considered herein is in the northwesterly flow of a jet streak, in the Northern Hemisphere, between an upstream ridge and downstream trough.

The mechanisms responsible for the excitation of these inertia-gravity waves remains a subject of research. The proposed mechanisms include adjustment from an unbalanced to a balanced state (geostrophy or a higher-order balance) (e.g., Uccellini and Koch 1987; Zhang 2004), and nonlinear forcing analogous to Lighthill radiation (Reeder and Griffiths 1996). All of these proposed excitation mechanisms characteristically take place in regions of strong jets associated with baroclinic waves.

The specific details of the above wave source mechanism are not the focus of this study. Instead, this study focuses on a jet stream/upper-level front that was observed during the Severe Clear-Air Turbulence Colliding with Aircraft Traffic (SCATCAT) experiment. SCATCAT was an experiment designed to examine CAT associated with jet streams and upper-level fronts. The National Oceanographic and Atmospheric Administration's (NOAA) Gulfstream-IV (G-IV) weather reconnaissance aircraft was the principal observing platform, encompassing high-resolution dropsonde releases and in situ measurements. On the 17-18 February 2001 flight, the G-IV observed an intense jet stream and an upper-level front, and encountered moderate CAT. The turbulence was encountered in a region of possible gravity wave activity.

This paper has two objectives. The first objective is to describe the detailed mesoscale structure of the jet/ front system that was observed surrounding 0000 UTC 18 February 2001. The second objective is to utilize finescale numerical simulations to examine the generation of inertia-gravity waves by the jet/front system and relate these waves to small-scale instabilities, to advance our knowledge of the role of inertia-gravity waves in generating CAT. It will be shown that the simulations compare qualitatively well to the observations, especially considering the paucity of data in the Pacific and the scales of motion involved. Although the simulations possess some limitations, they provide useful insight into the dynamical behavior of the observed system and the relationship between inertia-gravity waves and CAT.

The remainder of the paper is organized as follows. The observations from the G-IV surrounding 0000 UTC 18 February 2001 are presented (section 2), followed by a discussion of the synoptic-scale flow derived from a forecast (section 3). In section 4, a nested model is used to examine the finescale structure of the flow, including the jet, upper-level front, and inertia-gravity waves. It is shown that these waves are responsible for generating a Kelvin-Helmholtz instability. In section 5, the NOAA G-IV dropsondes are analyzed for inertiagravity waves to determine whether the inertia-gravity waves derived from the simulations are realistic. Finally, the results are summarized in section 6 .

\section{Dropsonde observations: 17-18 February 2001}

Surrounding 0000 UTC 18 February 2001, the G-IV observed an intense jet stream/frontal system over the Pacific Ocean at approximately $40^{\circ} \mathrm{N}, 200^{\circ} \mathrm{E}$. During this flight, 17 closely spaced dropsondes were released between 2326 UTC 17 February 2001 and 0024 UTC 18 February 2001 with an average horizontal separation of approximately $40 \mathrm{~km}$. The flight track of the G-IV during the dropsonde deployment is shown in Fig. 1; the G-IV was initially flying to the north, then turned to the northeast. Also shown in Fig. 1 is the approximate location of the jet stream at 0000 UTC 18 February, derived from a 24-h forecast from the Naval Research Laboratory's Coupled Ocean-Atmosphere Mesoscale Prediction System (COAMPS; see Hodur 1997). (COAMPS and its configuration are described in section 3.) The 17 dropsonde profiles were combined to form a vertical cross-section analysis. The close separation of these sondes along with their high vertical resolution permits the analysis of coherent structures. In order to construct this cross-section analysis, the profile from each sonde was interpolated onto a regular vertical grid with 50-m spacing. These data were then filtered to remove signals with vertical scales of motion less than $250 \mathrm{~m}$. Each sonde was assigned a distance along the flight track (relative to the first sonde released) using its release position. The resulting cross sections of potential temperature and wind speed are shown in Fig. 2. Three of the 17 sondes did not record winds. At the 


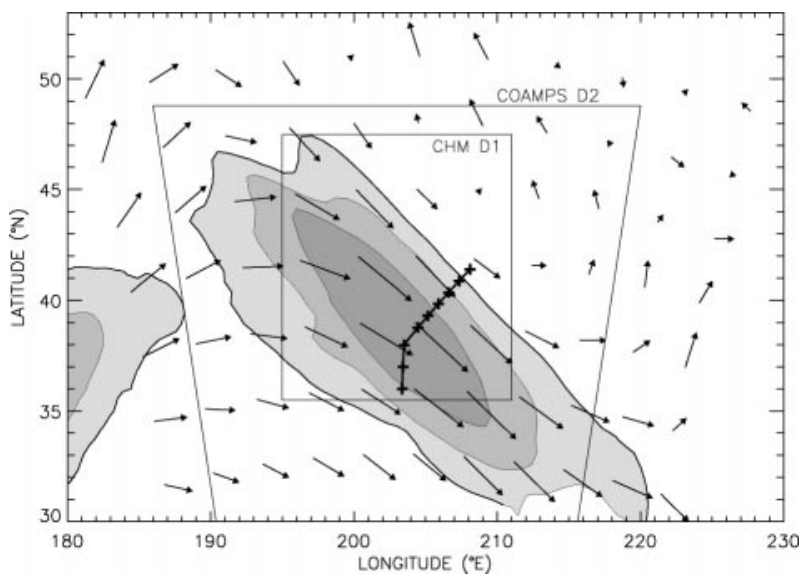

FIG. 1. The G-IV flight track during the dropsonde deployment (thick line) and the release point of every second dropsonde (crosses). Position of the jet stream at 0000 UTC 18 Feb 2001 from a COAMPS 24-h forecast, illustrated by the $9 \mathrm{~km}$ AMSL wind vectors and wind speed contoured and shaded at 50,60 , and $70 \mathrm{~m} \mathrm{~s}^{-1}$. Also shown is the location of COAMPS domain 2, and the CHM domain 1.

top of each sounding, there is one data point at the release height determined from the G-IV in situ flight data, and because it takes a finite time for the sonde to reach equilibrium with its environment, there is a layer of missing data about $1 \mathrm{~km}$ thick below flight level. The data are interpolated across this layer of missing data.

Figure 2 shows the detailed structure of the jet/front system. The observed maximum wind speed of the jet exceeds $100 \mathrm{~m} \mathrm{~s}^{-1}$, with its core at approximately $9 \mathrm{~km}$ above mean sea level (AMSL). There is also evidence of a weaker jet $\left(65 \mathrm{~m} \mathrm{~s}^{-1}\right)$ at approximately $5.5 \mathrm{~km}$ AMSL. The frontal zone below the jet is between approximately 2 and $6 \mathrm{~km}$ AMSL, and tilts at about 100:1 (horizontal:vertical). Above the jet are perturbations in potential temperature that may be due to gravity waves. These perturbations are in the region just to the cyclonic (northeast) side of the jet core, extending to the anticyclonic side (southwest). A line that represents a possible tilting phase structure is also shown overlaid in Fig. 2a. Above and below the jet core, the vertical shear is large and exceeds approximately $20 \mathrm{~m} \mathrm{~s}^{-1} \mathrm{~km}^{-1}(0.02$ $\mathrm{s}^{-1}$ ). The negative (speed) shear above the jet is generally stronger than the positive (speed) shear below.

After deploying the dropsondes, the G-IV completed stacked flight legs in the region of possible gravity waves above the jet core. During these stacked legs the G-IV encountered moderate CAT. Regions of CAT that induced vertical accelerations of the G-IV that exceeded $4.9 \mathrm{~m} \mathrm{~s}^{-2}(0.5 \mathrm{~g}$ 's $)$ in magnitude are also shown in Fig. 2a. These regions of turbulence coincide with the strong negative shear region above the jet, and the perturbations in potential temperature that may be gravity wave induced. A detailed examination of the turbulence and in situ data from the G-IV can be found in Koch et al. (2003) and Koch et al. (2004, manuscript submitted to J. Atmos. Sci.).
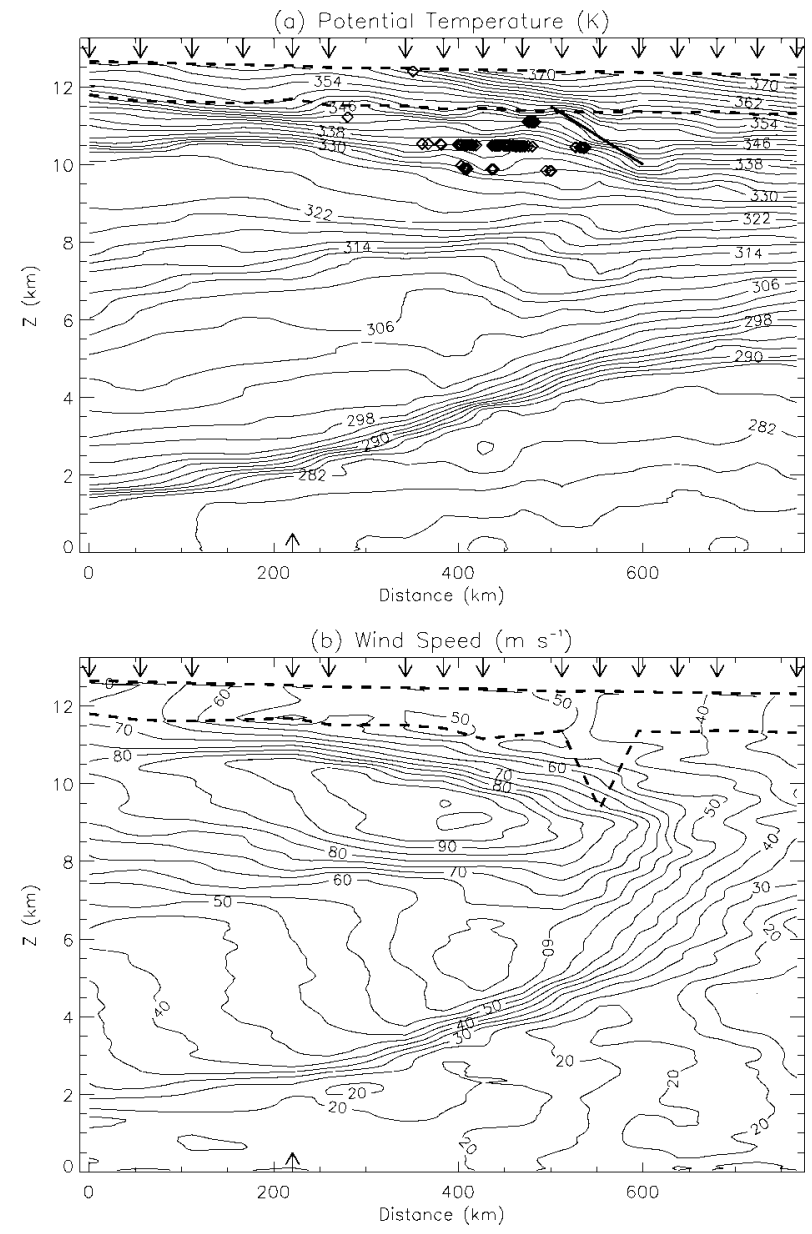

FIG. 2. Cross sections of (a) potential temperature and (b) wind speed derived from the dropsondes. The horizontal axes run from the southwest to the northeast along the flight track shown in Fig. 1. The locations of the dropsondes with good thermodynamic and wind data are shown by the downward-pointing arrows. The upward-pointing arrow marks the change in direction of the G-IV shown in Fig. 1. The thick dashed lines mark the flight level and first level of good data. Also shown in (a) is a line that represents a possible gravity wave phase line, and regions where the G-IV encountered vertical accelerations that exceeded $4.9 \mathrm{~m} \mathrm{~s}^{-2}$ in magnitude (diamonds).

\section{The synoptic-scale flow}

COAMPS is used to analyze and forecast the evolving three-dimensional flow surrounding the observations. This numerical model is a finite-difference approximation to the fully compressible, nonhydrostatic equations and uses a terrain-following vertical coordinate transformation. The finite-difference schemes are of second-order accuracy in time and space. Reflection of waves at the upper boundary is mitigated by a radiation condition following Klemp and Durran (1983) and Bougeault (1983). The simulations use a full suite of physical parameterizations to represent boundary layer, radiative, and moist processes (e.g., Hodur 1997; Hodur and Doyle 1999).

For this experiment, COAMPS is configured with two 


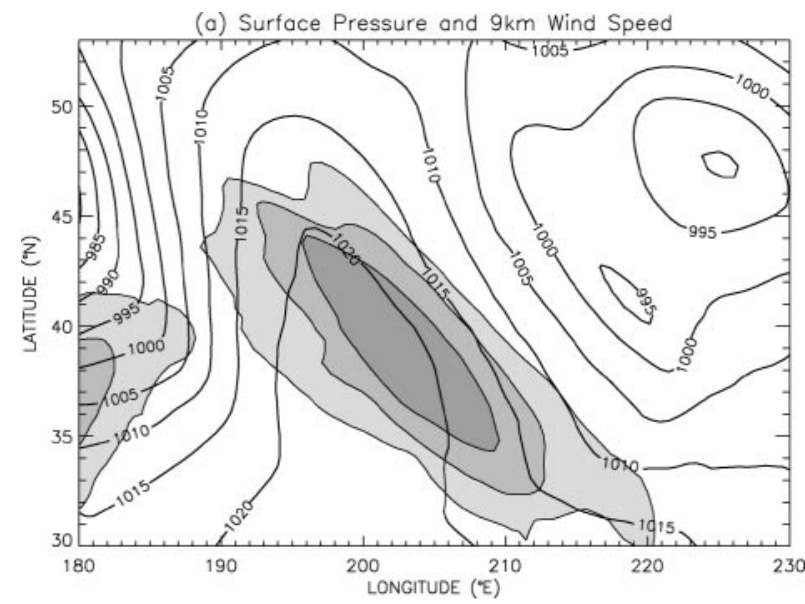

(b) $800-600 \mathrm{mb}$ Thickness and $9 \mathrm{~km}$ Wind Speed

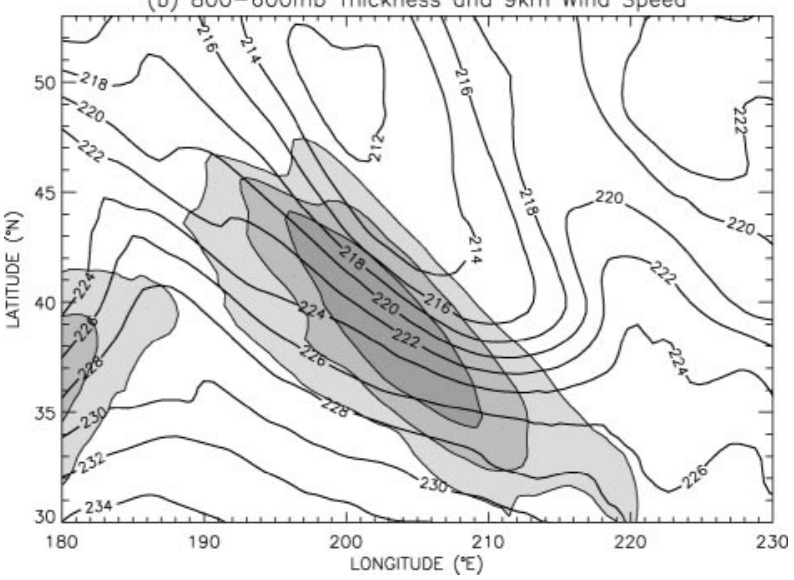

FIG. 3. (a) Surface pressure (mb) and (b) the 800-600-mb thickness (dam) at 0000 UTC 18 Feb 2001, from the COAMPS (domain 1) 24-h forecast. Also shown in both plots is the $9 \mathrm{~km}$ AMSL wind speed contoured and shaded at 50,60 , and $70 \mathrm{~m} \mathrm{~s}^{-1}$.

horizontally nested domains of $97 \times 73$ and $133 \times 133$ points, with horizontal grid spacings of 54 and $18 \mathrm{~km}$, respectively. The model upper boundary is at $30 \mathrm{~km}$ with 80 vertical levels, with a vertical grid spacing of $10 \mathrm{~m}$ at the lowest level stretched to $400 \mathrm{~m}$ aloft. The forecast is initialized at 0000 UTC 17 February 2001. The initial fields for the model are created from multivariate optimum interpolation analyses of upper-air sounding, surface, aircraft, and satellite data that are quality controlled and blended with the 12-h COAMPS forecast fields. Lateral boundary conditions make use of the Navy Operational Global Analysis and Prediction System forecast fields following Davies (1976).

Figures 1 and 3 show the synoptic features from domain 1 of COAMPS at 0000 UTC 18 February 2001 (24-h forecast). At this time, the jet that is the focus of this study flows from the northwest, downstream of the surface high and upstream of the surface cyclone (Fig. 3a). An upper-level front is associated with this jet. This front is aligned with the jet, as shown by the 800-600mb thickness (Fig. 3b). As expected from the thermal
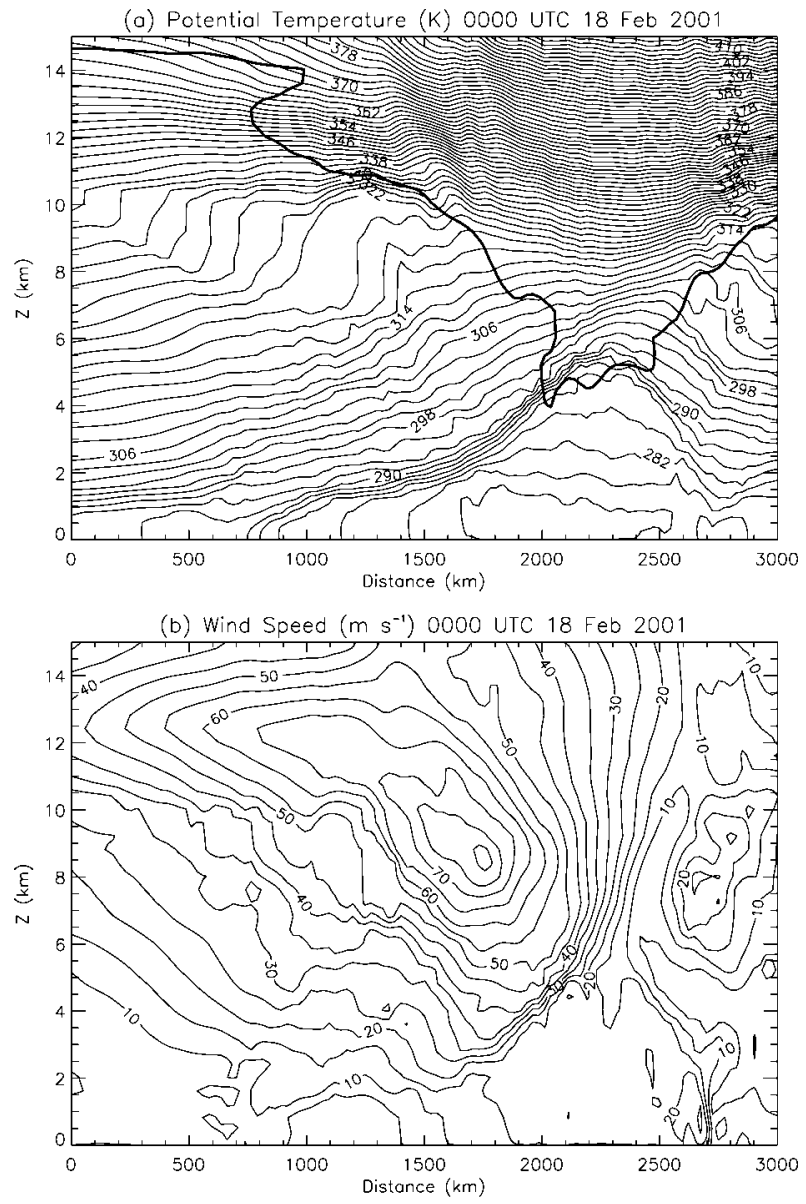

FIG. 4. Cross sections of (a) potential temperature and (b) wind speed from COAMPS (domain 2) at 0000 UTC 18 Feb 2001. The cross section is between the southwest and northeast corners of the model domain (see Fig. 1). Also shown in (a) is the 2-PVU contour of potential vorticity (thick line).

wind balance, the front has strong gradients in potential temperature perpendicular to the jet on its cyclonic (northeast) side.

The vertical structure of the jet/front system is shown in southwest to northeast cross sections at 0000 and 0600 UTC (Figs. 4 and 5, respectively). At 0000 UTC (Fig. 4) the jet maximum is at about $8 \mathrm{~km}$ AMSL and the maximum wind speed exceeds $80 \mathrm{~m} \mathrm{~s}^{-1}$. There are strong horizontal shears on the cyclonic side of the jet, and the isopleths are nearly vertical. Below the jet is the upper-level front with its strong horizontal and vertical gradients in both wind speed and potential temperature. Also, the height of the tropopause descends significantly from its background height of about 10$14 \mathrm{~km}$, into a deep fold on the cyclonic side of the jet, following the front to about $4 \mathrm{~km}$. On the anticyclonic side of the jet core, the static stability in the upper troposphere is very low over a depth of about $3 \mathrm{~km}$ and $500-1000 \mathrm{~km}$ in length.

At 0600 UTC (Fig. 5), the jet/front system has a similar 
(a) Potential Temperature (K) 0600 UTC 18 Feb 2001

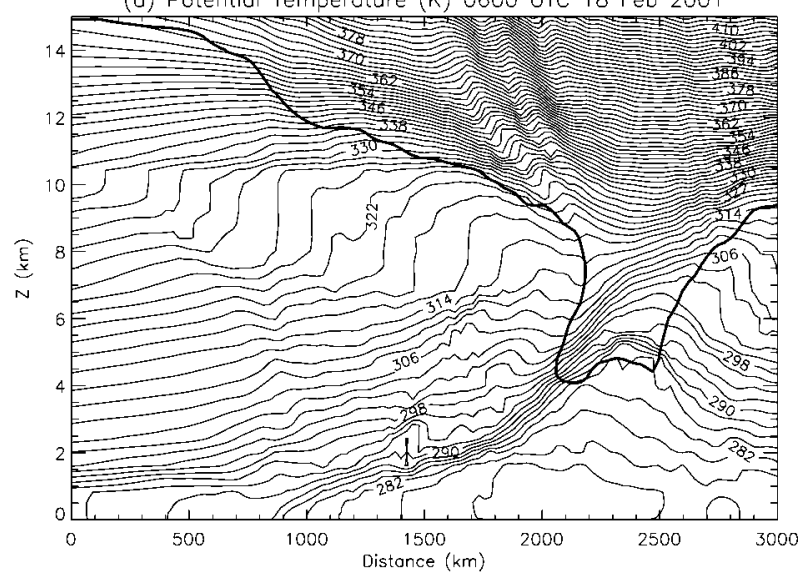

(b) Wind Speed $\left(\mathrm{m} \mathrm{s}^{-1}\right) 0600$ UTC 18 Feb 2001

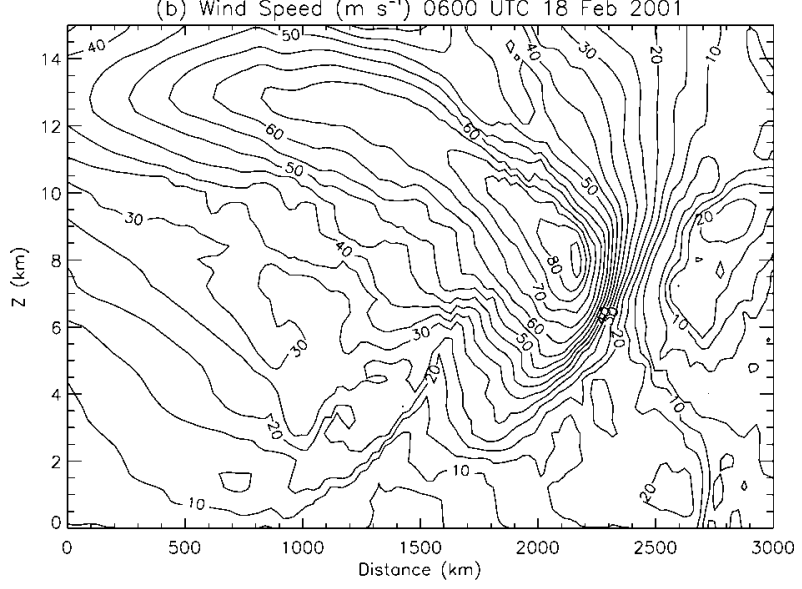

FIG. 5. Same as in Fig. 4 except at 0600 UTC 18 Feb 2001.

structure to that of 0000 UTC (Fig. 4). However, the jet is faster and, subsequently, the vertical shears above and below and the horizontal shear on the cyclonic side of the jet are greater. The frontal baroclinicity intensifies and steepens. The tropopause fold maintains its vertical extent but has broadened in the horizontal. Of special importance to this study are strong perturbations in the potential temperature that extend vertically into the stratosphere above the jet core. These perturbations are the signature of vertically propagating inertia-gravity waves with horizontal wavelengths (in this southwest to northeast plane) of about $250 \mathrm{~km}$. These waves are discussed in further detail in section 4.

The simulated structure of the jet/front system (Figs. 4 and 5) is qualitatively similar to that shown in the dropsonde analysis (Fig. 2). However, there are some differences; for example, the speed of the jet is underrepresented, and the simulated upper front develops about $6 \mathrm{~h}$ later than observed. Also, the modeled upper front is steeper than the observations and tilts at about 60:1 (horizontal:vertical). These differences are expected considering the model's location in the datasparse Pacific and are not a major concern. In the model the amplitude of the inertia-gravity waves at 0600 UTC is largest. Therefore, even though our observations surround 0000 UTC, we have selected 0600 UTC as the focus of our further modeling efforts and analyses, and our comparisons to the observations will be qualitative.

\section{Finescale modeling}

In the previous section, the synoptic forecast produced inertia-gravity waves above the jet/upper-front system. In this section, a finescale nested model (the Clark-Hall model) is used to better resolve the upper front, inertia-gravity waves, and possible CAT generation.

\section{a. The Clark-Hall model and nesting procedures}

The Clark-Hall model (CHM; Clark 1977; Clark et al. 1996) is a nonhydrostatic, anelastic finite difference mesoscale model. In this study, it is configured in three dimensions, warm-rain cloud processes are treated using the Kessler (1969) scheme, and the subgrid mixing is the Smagorinsky (1963)-Lilly (1962) closure. Radiative and surface fluxes are neglected. The CHM is capable of two-way nesting (Clark and Hall 1991), which includes refinement in both the horizontal and vertical, as well as at elevated domains. This feature of the model allows small-scale features to be examined in significant detail, while still allowing larger-scale features to evolve realistically.

One other feature of the CHM is its ability to be (one way) nested within an operational-style model. In this study, COAMPS provides initial conditions to the CHM. At subsequent times, the COAMPS model fields are used as boundary conditions for the CHM outermost domain. These boundary conditions are constructed using linear interpolation from hourly COAMPS data. [A more detailed description of the way the CHM is forced by a larger-scale model is found in Clark et al. (2000).]

The horizontal locations of the CHM domains used in this study are shown in Fig. 6, and their geometries are summarized in Table 1. (Note, each model grid uses constant $\Delta$ latitude and $\Delta$ longitude spacing, and therefore although $\Delta Y$ is constant, $\Delta X$ is a function of latitude. $\Delta X=\Delta Y \cos \left(\right.$ latitude) $/ \cos (41.5)$, where $41.5^{\circ} \mathrm{N}$ is the latitude at the center of the outermost domain.) Not all domains are used in all experiments and we denote experiment $n$ as a model simulation that uses $n$ domains only. The vertical grid spacing in domain 1 was chosen to match that of COAMPS; this configuration reduces mismatches between COAMPS and the CHM near the lateral boundaries of CHM domain 1 . The uppermost $10 \mathrm{~km}$ of CHM domain 1 includes a Rayleigh friction absorber to reduce reflection of disturbances from the upper boundary. Domain 3 has the same horizontal grid spacing as domain 2, but smaller vertical grid spacing. This domain configuration provides a smoother transition from domain 1 to 3 by reducing inner-domain boundary effects, and allowing an 


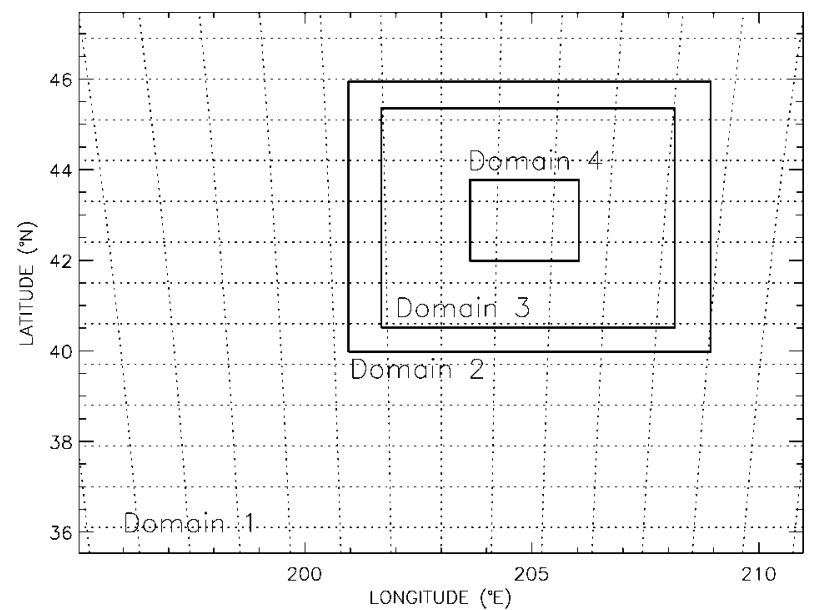

FIG. 6. The horizontal location of CHM domains 2-4 within domain 1 (see Fig. 1). Also shown is a grid (dashed); each element of the grid has dimensions of $100 \mathrm{~km} \times 100 \mathrm{~km}$.

effective 4:1 refinement in the vertical. Domain 3 is used for most of the analysis of the jet/front system, and domain 4 is used to examine shearing instabilities in the region of the inertia-gravity waves. Although there are only a few clouds in the CHM domain, the explicit microphysics of the CHM (i.e., no cumulus parameterization) restricts the horizontal grid spacing of domain 1. The horizontal grid spacing of $6 \mathrm{~km}$ was found to be about the largest grid spacing that did not produce problematic results due to improper treatment of cloud evolution.

\section{b. High-resolution simulation with the Clark-Hall model}

Figure 7 presents a cross section of simulated potential temperature (Fig. 7a) and wind speed (Fig. 7b) from CHM domain 3 at 0600 UTC for experiment 3. The potential temperature identifies the front, which is strongest between 4 and $8 \mathrm{~km}$. The strongest part of the front is associated with a deep tropopause fold that extends downward to $4 \mathrm{~km}$. The background tropopause height ranges from $5 \mathrm{~km}$ on the northeast side of the front to $10 \mathrm{~km}$ on the southwest side. In addition to the deep tropopause fold, there is a shallow secondary fold (at around 400-km distance and $8 \mathrm{~km}$ AMSL), and undulations in the tropopause on the anticyclonic side of the secondary fold. These undulations have a horizontal scale of around $150 \mathrm{~km}$. The wind speed shows the jet core

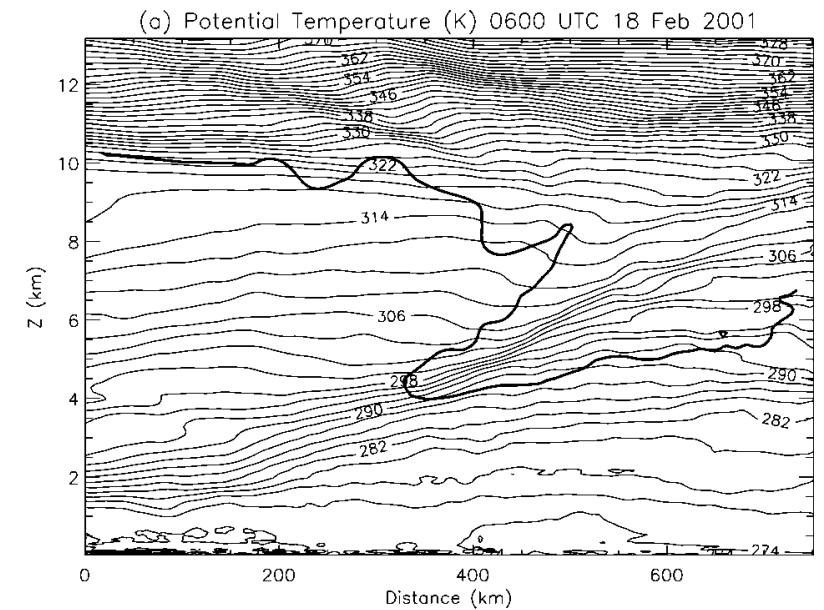

(b) Wind Speed $\left(\mathrm{m} \mathrm{s}^{-1}\right) 0600$ UTC 18 Feb 2001

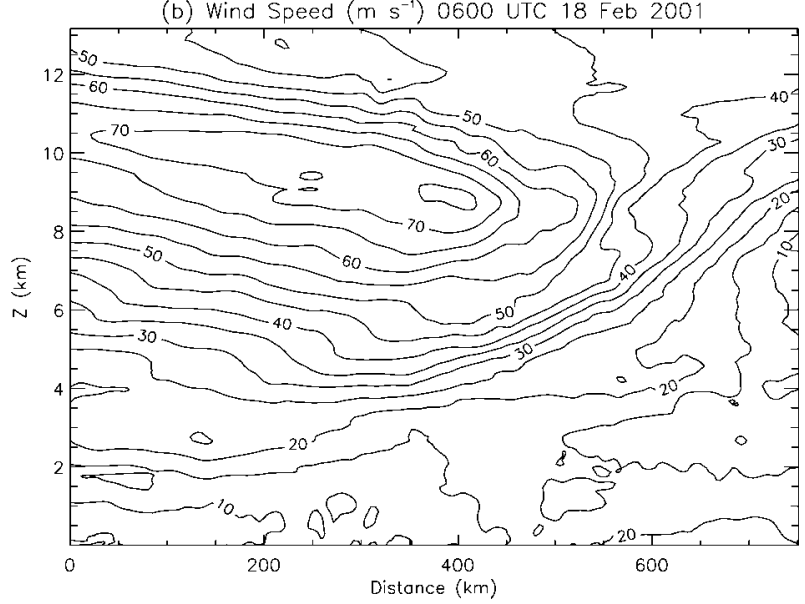

FIG. 7. Cross sections of (a) potential temperature and (b) wind speed from CHM (domain 3, experiment 3) at 0600 UTC 18 Feb 2001. The cross section is between the southwest and northeast corners of the model domain (see Fig. 6). Also shown in (a) is the 2PVU contour of potential vorticity (thick line).

to be at about $9 \mathrm{~km}$ AMSL, and through this cross section the maximum wind speed is about $75 \mathrm{~m} \mathrm{~s}^{-1}$ (although the maximum wind speed in the domain is about 85 $\mathrm{m} \mathrm{s}^{-1}$ ). The vertical wind shear is maximized above the jet and within the frontal zone associated with the tropopause fold. In these regions, the vertical shear exceeds $20 \mathrm{~m} \mathrm{~s}^{-1} \mathrm{~km}^{-1}\left(0.02 \mathrm{~s}^{-1}\right)$. In addition to these vertical shears, the jet exhibits two regions of localized cyclonic shear at the level of maximum wind $(9 \mathrm{~km})$ at distances of $\sim 425$ and $\sim 550 \mathrm{~km}$. These horizontal shear zones are within the secondary and deep tropopause folds. The

TABLE 1. Geometry of the CHM domains: the meridional grid spacing $(\Delta Y)$, vertical grid spacing $(\Delta Z)$, lateral dimensions $(\mathrm{NX}=\mathrm{NY})$, vertical dimensions (NZ), lowermost domain level $\left(Z_{0}\right)$, uppermost domain level $\left(Z_{M}\right)$, and domain initialization time $T_{0}$.

\begin{tabular}{cccccccc}
\hline \hline Domain & $\Delta Y(\mathrm{~km})$ & $\Delta Z(\mathrm{~m})$ & $\mathrm{NX}$ & $\mathrm{NZ}$ & $Z_{0}(\mathrm{~km})$ & $Z_{M}(\mathrm{~km})$ & $T_{0}$ \\
\hline 1 & 6 & 400 & 222 & 92 & 0 & 33.6 & 1800 UTC 17 Feb \\
2 & 3 & 200 & 222 & 120 & 0 & 21.2 & 0000 UTC 18 Feb \\
3 & 3 & 100 & 180 & 160 & 0 & 13.3 & 0000 UTC 18 Feb \\
4 & 1 & 50 & 200 & 100 & 8 & 12.9 & 0400 UTC 18 Feb \\
\hline
\end{tabular}



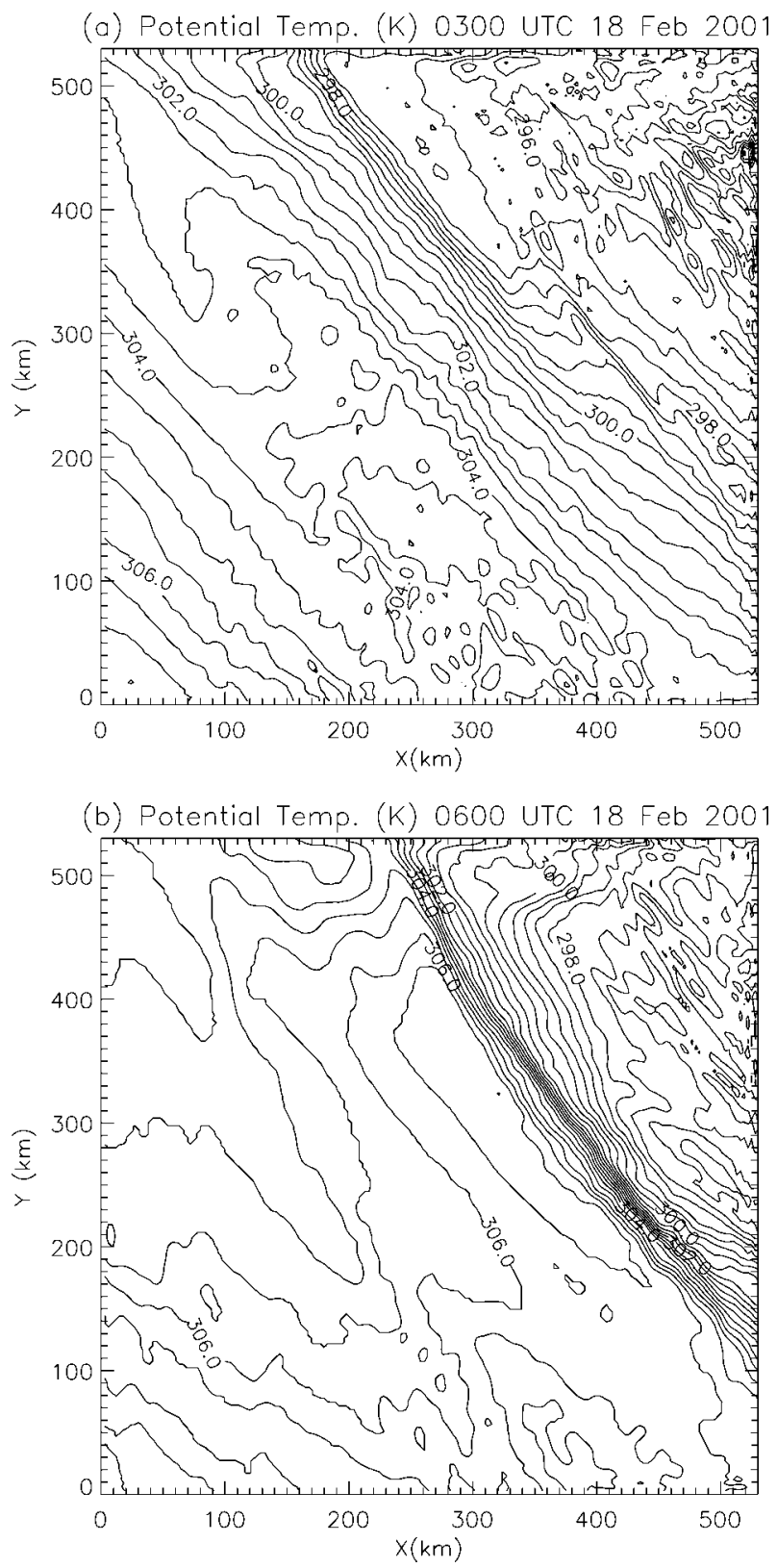

FIG. 8. Horizontal cross sections of potential temperature through $6 \mathrm{~km}$ AMSL at (a) 0300 and (b) 0600 UTC from CHM (domain 3, experiment 3 ). The contour interval is $0.5 \mathrm{~K}$.

overall shape of the jet is similar to that analyzed from the dropsonde observations; however, the modeled jet is weaker and therefore the modeled vertical shears above and below the jet are also weaker than observed.

The simulation shows evidence of vertically propagating inertia-gravity waves, which appear as wavelike perturbations in the potential temperature above the jet core, extending to its anticyclonic side (see Fig. 7a). Like the COAMPS forecast, these waves appear after 0000 UTC and their amplitude increases a few hours before 0600 UTC; their amplitudes are maximized at 0600 UTC.

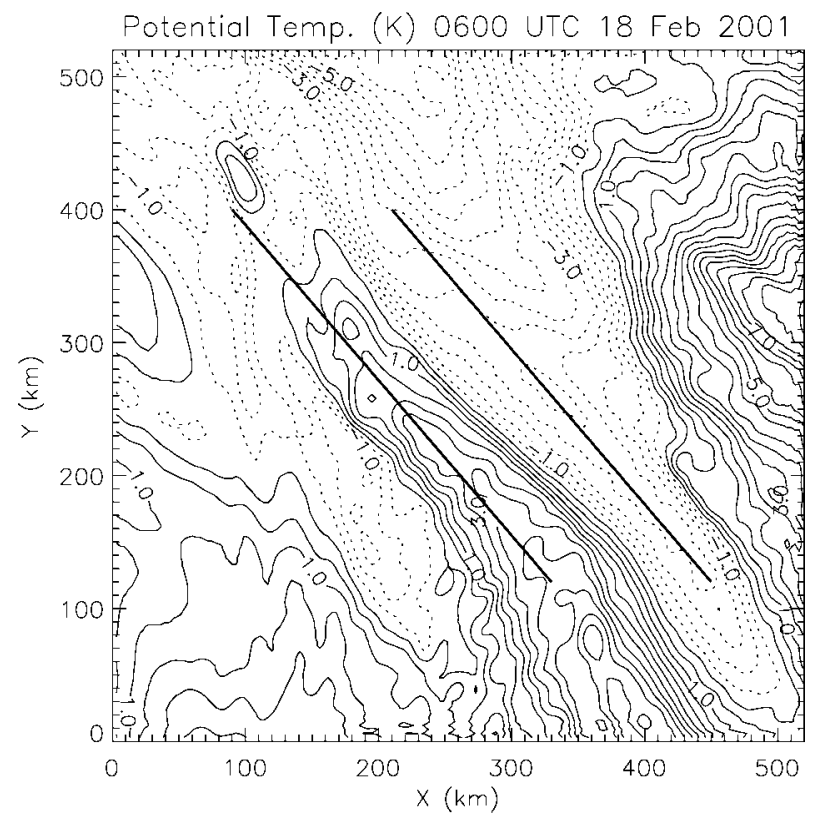

FIG. 9. Horizontal cross section of potential temperature through $11 \mathrm{~km}$ AMSL at 0600 UTC from CHM (domain 3, experiment 3). To assist with interpretation, the potential temperature is contoured as the perturbation from $335 \mathrm{~K}$ with negative values dashed. The contour interval is $0.5 \mathrm{~K}$. Also shown are lines that approximate lines of constant gravity wave phase.

This increase in wave amplitude coincides with rapid upper-level frontogenesis. The intensification of the front is illustrated in Fig. 8, which shows the 6-km potential temperature. At 0300 UTC, the upper front is forming, with the strongest horizontal gradients at its northwestern end. In time, these gradients progressively increase along the front from the northwest, until 0600 UTC when the front has intensified with strong horizontal gradients along its entire length. The mature front is oriented parallel to the jet from the northwest to southeast.

\section{c. Analysis of inertia-gravity waves from the simulation}

The inertia-gravity waves in Fig. 7a appear as a quasimonochromatic wave packet with approximately two horizontal wavelengths evident. The phase lines of this wave tilt toward the southwest, implying vertical propagation. Using Fig. 7a, the vertical wavelength of this wave, in the lower stratosphere, is estimated to be approximately $2.5 \mathrm{~km}$. Therefore, $|m|=2.513 \times 10^{-3}$ $\mathrm{rad} \mathrm{m}^{-1}$, and assuming upward energy propagation and positive intrinsic frequency $m$ is negative.

Figure 9 illustrates the horizontal structure of the waves using the 11-km AMSL potential temperature from domain 3 of experiment 3. Also shown in this figure are two lines that represent lines of constant inertia-gravity wave phase, passing through adjacent wave maxima and minima. The amplitude of the waveinduced perturbations in potential temperature is ap- 
proximately $3 \mathrm{~K}$. Using Fig. 9 the zonal wavelength is estimated to be approximately $240 \mathrm{~km}$, and the meridional wavelength is approximately $280 \mathrm{~km}$. The horizontal wave vector, $\mathbf{K}_{\mathrm{H}}=(k, l)$, is perpendicular to the lines of constant phase, and the direction of the vertical tilt shown in Fig. 7a implies that the horizontal wave vector points to the southwest. Therefore, $\mathbf{K}_{\mathrm{H}}=$ $(-2.618,-2.244) \times 10^{-5} \mathrm{rad} \mathrm{m}^{-1},\left|\mathbf{K}_{\mathrm{H}}\right|=3.448 \times$ $10^{-5} \mathrm{rad} \mathrm{m}^{-1}$, and the horizontal wavelength $\lambda_{\mathrm{H}} \approx 180$ $\mathrm{km}$. This estimate of $\lambda_{\mathrm{H}}$ is consistent with measurements from Figs. 7a and 9.

The dispersion relation for nonhydrostatic gravity waves with rotation is

$$
\frac{m^{2}}{k^{2}+l^{2}}=\frac{N^{2}-\hat{\omega}^{2}}{\hat{\omega}^{2}-f^{2}},
$$

where $N$ is the Brunt-Väisälä frequency, $\hat{\omega}$ is the intrinsic frequency of the gravity wave, and $f$ is the Coriolis parameter. Making the hydrostatic approximation $\left(k^{2}+l^{2} \ll m^{2}\right)$, the dispersion relation can be written as

$$
\hat{\omega}^{2}=\frac{N^{2}\left(k^{2}+l^{2}\right)}{m^{2}}+f^{2} .
$$

Therefore, using the estimates of $k, l$, and $m$ made earlier, $N=0.02 \mathrm{rad} \mathrm{s}^{-1}$ (a value representative of the modeled lower stratosphere) and $f=10^{-4} \mathrm{rad} \mathrm{s}^{-1}$, the intrinsic frequency is approximately $2.952 \times 10^{-4} \mathrm{rad} \mathrm{s}^{-1}$ and the intrinsic period is approximately $5.9 \mathrm{~h}$. These wave characteristics are extremely similar to those in other modeling studies such as those of Zhang (2004); however, the wave phase lines are oriented parallel to the jet, whereas the waves that were the focus of Zhang's study were perpendicular to the jet. Yet, F. Zhang (2004, personal communication) notes that gravity waves aligned with the northwesterly flow, like those considered here, are also present in his idealized simulation.

As mentioned earlier, the amplification of these inertia-gravity waves coincides with the intensification of the upper front. Also, the wave phase lines are approximately aligned with the upper front (e.g., Figs. 8 and 9). These two features of the inertia-gravity waves imply that the waves are indeed generated by upper-level frontogenesis. However, the mesoscale features of the jet/front system, including the horizontal shear layers adjacent to the jet and the associated deep and secondary tropopause folds, possess horizontal scales similar to the generated inertia-gravity waves. Without a sophisticated source analysis it is difficult to determine un- ambiguously whether the mesoscale structures are the source of the gravity waves or a response to some other forcing that is also generating the waves. Such source analysis is beyond the scope of this study, but is an area of active research.

Einaudi and Lalas (1975) showed that a wave propagating through an almost neutral atmosphere can significantly affect the local Richardson number ( $\mathrm{Ri}$ ) and possibly induce shearing instabilities. In the case presented here, the atmosphere is stably stratified, yet in the region above the jet core the wind shear is sufficiently strong that the Richardson number is uniformly low ( $\mathrm{Ri}$ $\sim 2$ ). The Richardson number is defined as $N^{2} /|\operatorname{Def}|^{2}$, where $N$ is the Brunt-Väisälä frequency and $\mid$ Def $\mid$ is the magnitude of the total deformation, but at the scales of motion considered herein,

$$
\mathrm{Ri}=\frac{N^{2}}{\left(\frac{\partial u}{\partial z}\right)^{2}+\left(\frac{\partial v}{\partial z}\right)^{2}}
$$

where $u$ is the zonal velocity and $v$ is the meridional velocity, is a good approximation. If the horizontal velocity components and the potential temperature are separated into a background profile and a gravity waveinduced perturbation, the Richardson number can be written as

$$
\operatorname{Ri}=\frac{\frac{g}{\bar{\theta}}\left(\frac{d \bar{\theta}}{d z}+\frac{\partial \theta^{\prime}}{\partial z}\right)}{\left(\frac{d \bar{U}}{d z}+\frac{\partial u^{\prime}}{\partial z}\right)^{2}+\left(\frac{d \bar{V}}{d z}+\frac{\partial v^{\prime}}{\partial z}\right)^{2}},
$$

where the overbar denotes the background quantity and the prime denotes the perturbations. Assume that the wave perturbations in zonal velocity, meridional velocity, and potential temperature take the form

$$
\begin{aligned}
u^{\prime} & =A_{u} \cos \left(\phi+\alpha_{1}\right), \quad v^{\prime}=A_{v} \cos \left(\phi+\alpha_{2}\right), \quad \text { and } \\
\theta^{\prime} & =A_{\theta} \sin (\phi) .
\end{aligned}
$$

The wave phase is $\phi=k x+l y+m z-\hat{\omega} t ; \alpha_{1}$ and $\alpha_{2}$ are phase differences; and $A_{u}, A_{v}$, and $A_{\theta}$ are the wave amplitudes in zonal velocity, meridional velocity, and potential temperature, respectively. [These amplitudes and phase differences are not independent and are coupled via the polarization relations for an inertia-gravity wave (Gill 1982).] Invoking the Wentzel-Kramers-Brillouin (WKB) approximation (essentially $m=$ constant), the Richardson number can be written as

$$
\mathrm{Ri}=\frac{\frac{g}{\bar{\theta}}\left[\frac{d \bar{\theta}}{d z}+m A_{\theta} \cos (\phi)\right]}{\left[\frac{d \bar{U}}{d z}-m A_{u} \sin \left(\phi+\alpha_{1}\right)\right]^{2}+\left[\frac{d \bar{V}}{d z}-m A_{v} \sin \left(\phi+\alpha_{2}\right)\right]^{2}} .
$$




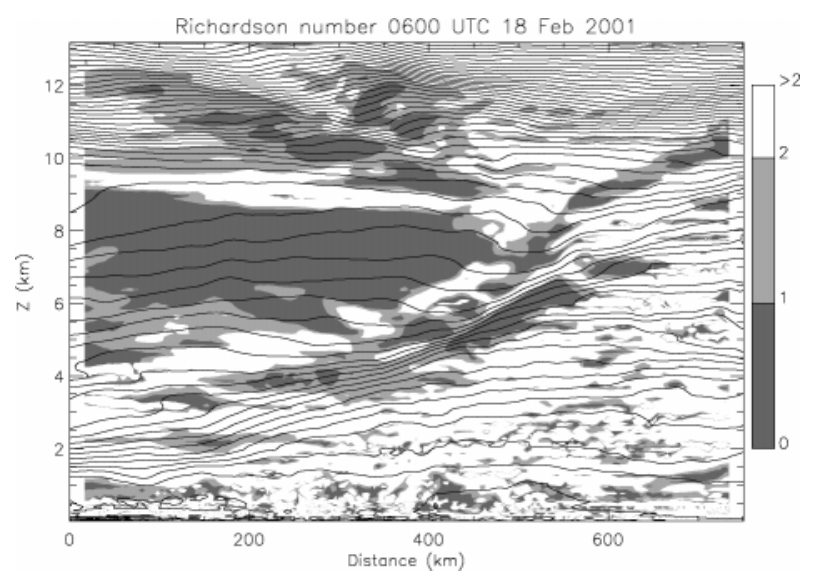

FIG. 10. Richardson number (shaded) at 0600 UTC 18 Feb 2001 from CHM (domain 3, experiment 3). The cross section is from the southwest to northeast corners of the domain (see Fig. 6). Also shown is potential temperature at $2-\mathrm{K}$ intervals.

Inertia-gravity waves will induce variations in the local Brunt-Väisälä frequency and vertical wind shear, which will in turn affect the Richardson number. Therefore, the Richardson number may be significantly affected by gravity-wave-induced perturbations if

$$
m A_{\theta} \sim \frac{d \bar{\theta}}{d z}, \quad m A_{u} \sim \frac{d \bar{U}}{d z}, \quad \text { or } \quad m A_{v} \sim \frac{d \bar{V}}{d z} .
$$

In the center of domain 3 of experiment 3 at 0600 UTC, between 10 and $12 \mathrm{~km}$ AMSL, $d \bar{\theta} / d z \approx 0.01 \mathrm{~K} \mathrm{~m}^{-1}$, $d \bar{U} / d z \approx-0.01 \mathrm{~s}^{-1}$, and $d \bar{V} / d z \approx 0.01 \mathrm{~s}^{-1}$. Also, from the simulation, the amplitudes of the inertia-gravity waves at $11 \mathrm{~km}$ AMSL are estimated as $A_{u} \approx 5 \mathrm{~m} \mathrm{~s}^{-1}$, $A_{v} \approx 5 \mathrm{~m} \mathrm{~s}^{-1}$, and $A_{\theta} \approx 3 \mathrm{~K}$. Therefore, using these quantities with the vertical wavenumber determined earlier $\left(m=-2.5 \times 10^{-3} \mathrm{rad} \mathrm{m}^{-1}\right)$, all three of the above conditions are met, implying that the inertia-gravity waves may significantly affect the local Richardson number.

Consider a southwest to northeast cross section of $\mathrm{Ri}$ $\left(=N^{2} / \mid\right.$ Def $\left.\left.\right|^{2}\right)$ from domain 3 (experiment 3$)$ of the CHM (Fig. 10). This figure shows that in the lower stratosphere, in the region of vertically propagating waves, the Richardson number is perturbed significantly. Subsequently, the Richardson number field possesses coherent bands of reduced Richardson numbers $(\mathrm{Ri}<$ 1) and bands of increased Richardson numbers ( $\mathrm{Ri}>$ 2). These bands of reduced and increased Richardson numbers are aligned with the gravity wave phase lines. The bands of reduced Richardson numbers approximately coincide with the wave-induced reduction in stability, that is, in quadrature with the potential temperature perturbations. Thus, as the gravity waves propagate vertically through the strong negative shear region above the jet, they perturb the background flow significantly and cause coherent bands of low Richardson numbers $(<1$ and $<1 / 4$ in some small regions). These bands are regions of possible Kelvin-Helmholtz insta- bility and CAT. Thus, although these waves are not necessarily strong in amplitude, their high vertical wavenumber coupled with the large background wind shear and low background Richardson number allow them to induce a shearing instability. In an observational case study, Pavelin et al. (2001) also showed that inertiagravity waves were responsible for generating a shearing instability. However, in Pavelin et al.'s study the environment possessed low wind shear (high background Richardson number), but the amplitude of the inertia-gravity waves was large enough to induce strong perturbations in wind shear and stability, reduce the Richardson number, and induce a shearing instability.

Figure 10 also shows a large region of $\mathrm{Ri}<1$ in the upper troposphere (altitudes between 6 and $9 \mathrm{~km}$ AMSL, and between $0-$ and $400-\mathrm{km}$ distance). This region is due to the strong shear below the jet core and the relatively low upper-tropospheric static stability. Other regions of low Richardson numbers also exist within the upper front.

Figure 11 shows the simulated fields from domain 4 at 0600 UTC 18 February 2001, for experiment 4, in the region above the jet where the inertia-gravity waves are affecting the Richardson number. The subgrid turbulent kinetic energy (TKE) (Fig. 11a) is inferred from the model eddy viscosity, $K_{M}$, using Deardorff's (1980) formulation: $\mathrm{TKE}^{1 / 2}=10 K_{M} l l$, where $l=\Delta Z=50 \mathrm{~m}$. Nonzero subgrid TKE exists in the strong shear above and below the jet, and in the region of the vertically propagating inertia-gravity waves. Like the bands of reduced Richardson numbers, the subgrid TKE is located in the region of the wave-induced reduction in stability, and also in regions where the potential temperature perturbation is negative. The subgrid TKE is not in exact quadrature with the perturbation potential temperature because of the contribution of the (background and wave perturbed) wind shear to the Richardson number. In this highest resolution domain, the subgrid TKE is not as coherent as may be expected from Fig. 10 because parts of the region of shear instability are mixed out by the resolved and parameterized flow. Figure 11b shows an estimate of the resolved TKE (RTKE), where RTKE $=\left(u^{\prime \prime 2}+v^{\prime \prime 2}+w^{\prime \prime 2}\right) / 2$. The perturbation velocities $u^{\prime \prime}, v^{\prime \prime}, w^{\prime \prime}$ are defined as deviations from a smoothed version of the background velocities. (This smoothing removes scales of motion that are less than $20 \mathrm{~km}$ in the horizontal.) The resolved TKE field identifies the existence of small-scale resolved motions $(<20 \mathrm{~km})$ that are stronger than the subgrid TKE and that are mixing out the shear instabilities in some regions. These small-scale motions are evident as small perturbations in the wind field (Fig. 11c).

The subgrid TKE is enhanced in two main regions. First, in horizontally coherent layers above and below the jet core in the regions of strongest vertical wind shear. These turbulent layers may not be related to the 

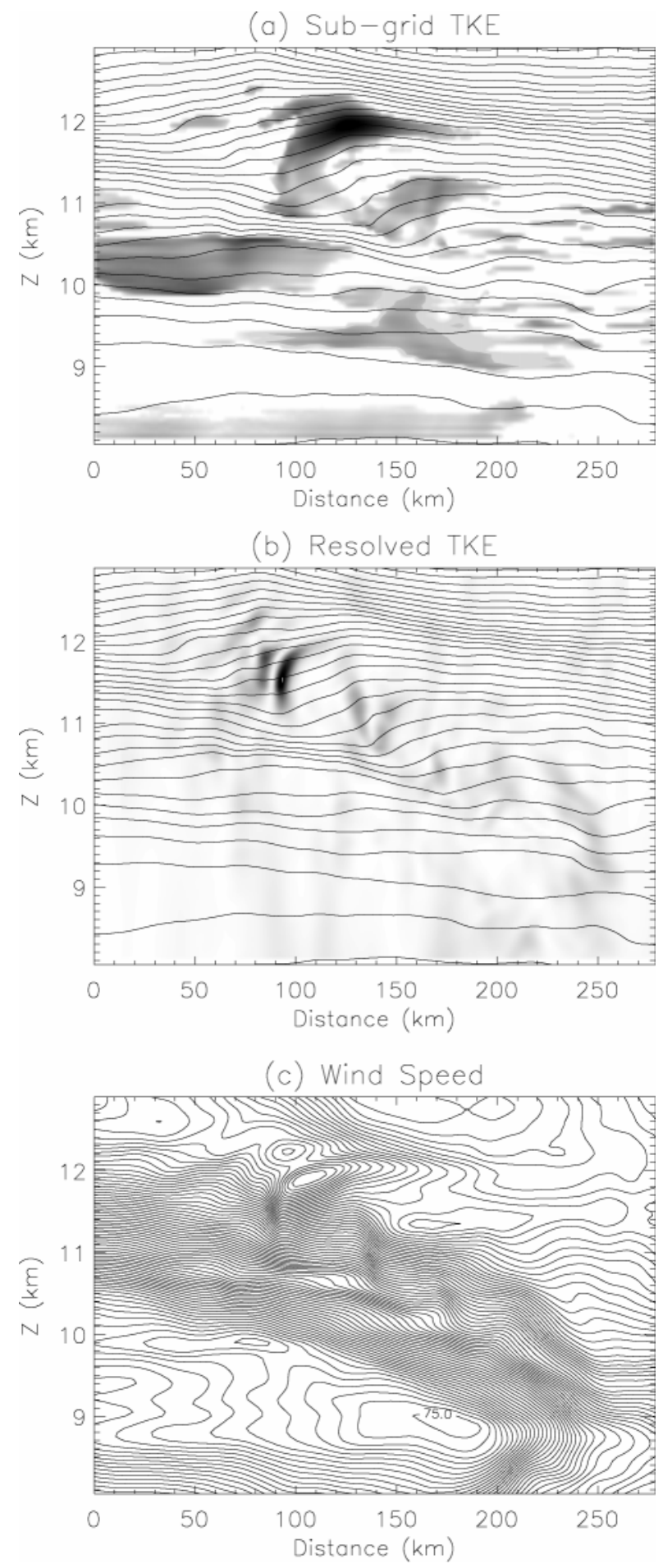

FIG. 11. Cross sections of (a) subgrid TKE, (b) resolved TKE, and (c) wind speed from CHM (domain 4, experiment 4) at 0600 UTC $18 \mathrm{Feb} 2001$. The cross section is from the southwest to northeast corners of the domain (see Fig. 6). In (a) and (b) the shading is linea with the maximum values of 0.2 and $0.7 \mathrm{~m}^{2} \mathrm{~s}^{-2}$ (respectively) marked by darkest shading. Wind speed contours in (c) are $0.5 \mathrm{~m} \mathrm{~s}^{-1}$. Also shown in (a) and (b) is potential temperature at $2-\mathrm{K}$ intervals.

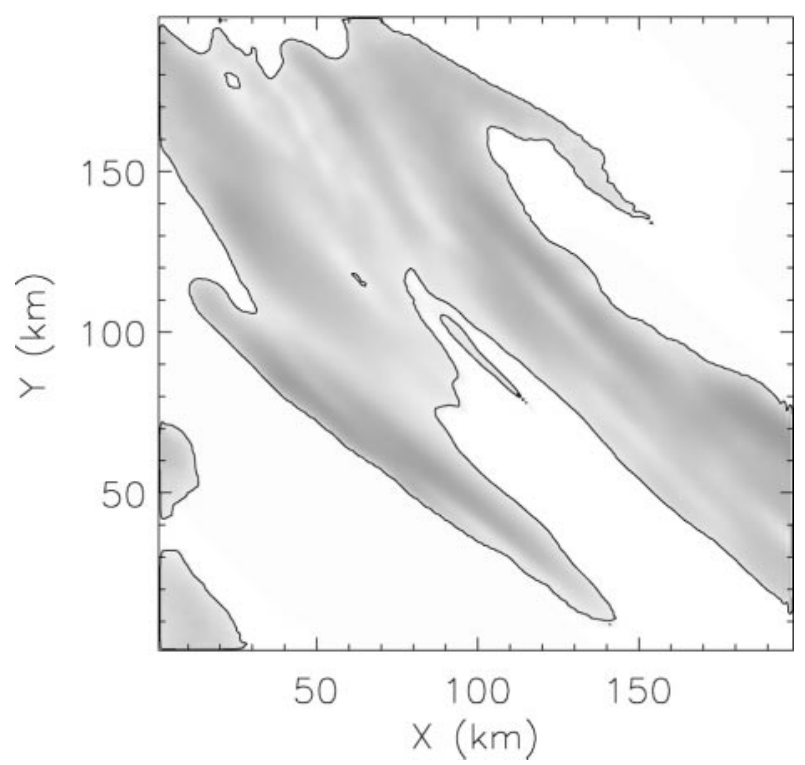

FIG. 12. Horizontal cross section of subgrid TKE through 11 km AMSL from CHM (domain 4, experiment 4) at 0600 UTC 18 Feb 2001. Shading is the same as in Fig. 11a, also shown is the $0.01 \mathrm{~m}^{2} \mathrm{~s}^{-2}$ contour.

inertia-gravity waves, and are not featured in the resolved TKE field. The second region is within the lowstability phase of the inertia-gravity waves, where both subgrid and resolved TKE are enhanced. The resolved TKE may be identifying growing modes associated with a Kelvin-Helmholtz instability. However, despite our efforts with nesting, the grid spacing in this domain is still too coarse to properly resolve the Kelvin-Helmholtz waves that are expected from such a shear instability. Also, the simulation time of this domain may be insufficient to properly spin up such motions.

At upper levels the subgrid TKE shown in Fig. 11a is located along the phase lines of the gravity waves, but the structures are incoherent or patchy in the vertical. However, a horizontal cross section of subgrid TKE (Fig. 12) shows a contiguous region of enhanced TKE with a relatively large area. The TKE field occurs in coherent bands that are oriented along the wave phase lines seen in Fig. 9. Therefore, the geometry of the volumes of enhanced TKE are complicated in shape, with larger horizontal extent than vertical and an aspect ratio that is qualitatively similar to that of the inertiagravity waves.

\section{d. Sensitivity of the modeled gravity waves to resolution}

To determine the robustness of the simulated gravity waves, numerous resolution sensitivity studies were completed by using only some of the coarser domains. For example, one simulation used domain 1 with no further nesting (experiment 1) and was integrated until 0600 UTC 18 February 2001. To test the effect of dou- 

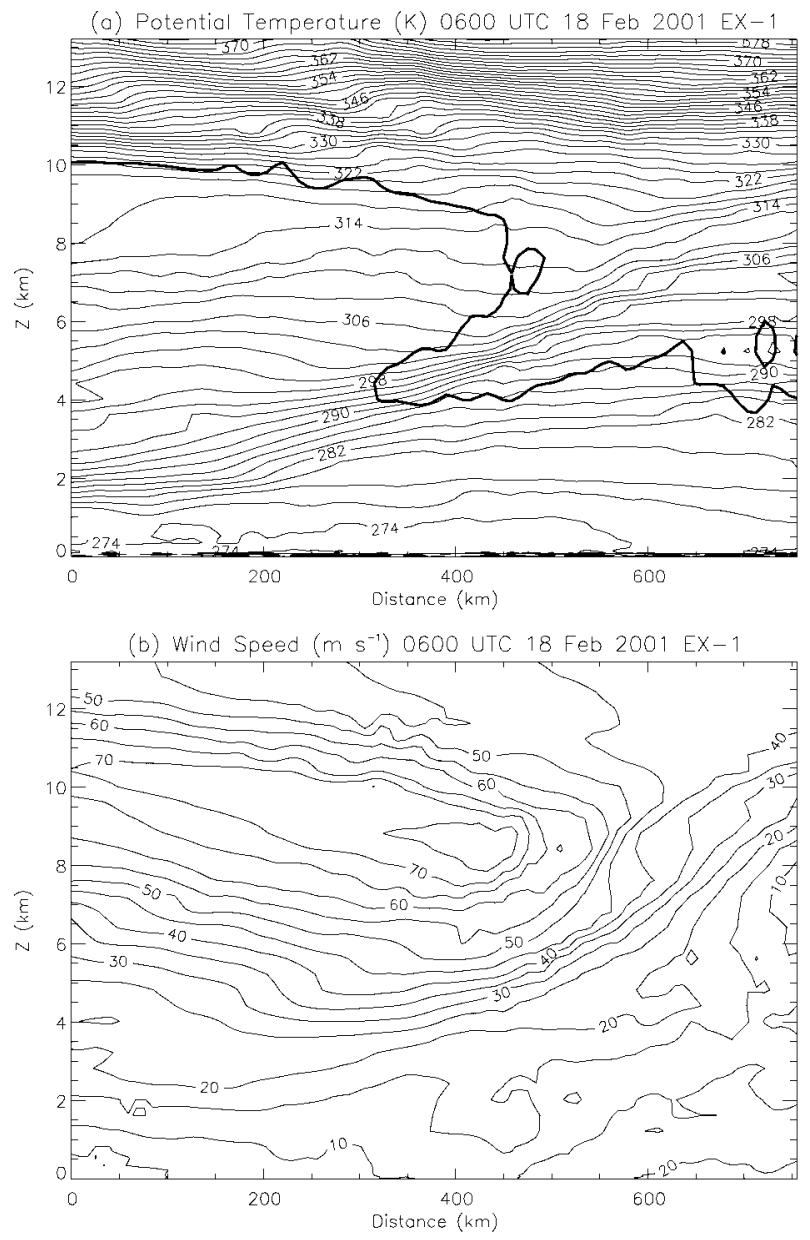

FIG. 13. Cross sections of (a) potential temperature and (b) wind speed from CHM experiment 1 (domain 1) at 0600 UTC 18 Feb 2001. The cross section is between the southwest and northeast corners of the model domain, only encompassing the horizontal extent of domain 3 (see Fig. 6). Also shown in (a) is the 2-PVU contour of potential vorticity (thick line).

bling both the vertical and horizontal resolution, experiment 2 incorporated domains 1 and 2 until 0600 UTC. The effect of doubling the vertical resolution again was further investigated in experiment 3 , which used domains 1-3. All of these experiments produced qualitatively similar results, with no major differences in the properties of the jet, upper front, or gravity waves.

For example, consider the results from experiment 1 at 0600 UTC (Fig. 13), through the same cross section as Fig. 7 (experiment 3). This comparison illustrates the effect of doubling the horizontal resolution and quadrupoling the vertical resolution. As expected, experiment 3 shows stronger gradients in potential temperature, stronger (horizontal and vertical) wind shears, and a well-defined secondary tropopause fold. Also, the gravity waves seem better resolved in experiment 3 , with the perturbations in potential temperature being smoother. There are minor differences in all fields; how- ever, the overall dynamics are the same. Therefore, it seems apparent that the results presented earlier from experiment 3 are relatively insensitive to resolution.

Previous studies (e.g., Lindzen and Fox-Rabinovitz 1989; Pecnick and Keyser 1989; Persson and Warner 1991) have discussed the importance of consistent vertical and horizontal resolution in the modeling of atmospheric flows, especially frontogenesis. Following Persson and Warner, we define a ratio

$$
A=\frac{\Delta Z / \Delta H}{S},
$$

where $S$ is the slope of the front (vertical/horizontal), $\Delta Z$ is the vertical grid spacing, and $\Delta H$ is the effective horizontal grid spacing in the cross-frontal direction. As shown by the previous studies, it is desirable that the front is resolved equally well in the horizontal and vertical, that is, $A \sim 1$. Otherwise, spurious waves may result. Persson and Warner showed that these spurious waves form on scales close to the grid scale.

Figure 8 shows that in this case the upper-level front is aligned northwest to southeast, and therefore the effective cross-frontal grid spacing becomes $\sqrt{2} \times \Delta Y$. As discussed earlier the modeled frontal zone has a slope $S \approx 1 / 60$ (vertical/horizontal), in the cross-frontal direction. The analysis has focused on domain 3, within which most of the upper-level frontogenesis occurs. Domain 3 has $\Delta H=\sqrt{2} \times 3 \mathrm{~km}, \Delta Z=100 \mathrm{~m}$, and, therefore, $A=1.4$, which is close to its most desirable value. Also, given that the results from the CHM are also insensitive to resolution, it seems reasonable to assume that the modeled inertia-gravity waves presented here are not spurious.

Although the intensification of the inertia-gravity waves coincides with upper-level frontogenesis (in domain 3 of the CHM), the waves may actually originate earlier from COAMPS. If that is the case, would the waves be spurious? COAMPS has $\Delta H=\sqrt{2} \times 18 \mathrm{~km}$, $\Delta Z=400 \mathrm{~m}$, and, therefore, $A \approx 0.94$, which is even closer to its most desirable value. Thus, if the gravity waves did originate from COAMPS, they are not likely to be spurious either.

\section{Analysis of the dropsondes for gravity waves}

In this section, the NOAA G-IV dropsondes are analyzed for inertia-gravity waves to determine whether the waves in the simulations are consistent with the observations.

The close spacing of the dropsondes shown in Fig. 2 allows the detailed mesoscale structure of the jet/front to be elucidated, including intense horizontal shear zones, and possible coherent phase structures of gravity waves. However, the spacing of the dropsondes is too large to properly sample waves with horizontal wavelengths of approximately $100 \mathrm{~km}$, and the release height of the sondes is not high enough to identify coherent phase lines in the lower stratosphere such as those in 


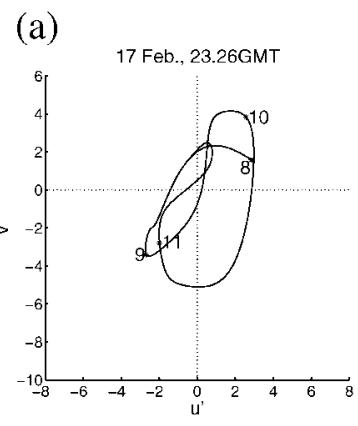

(d) (b)

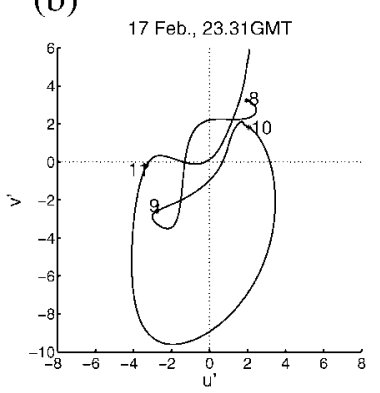

(c)

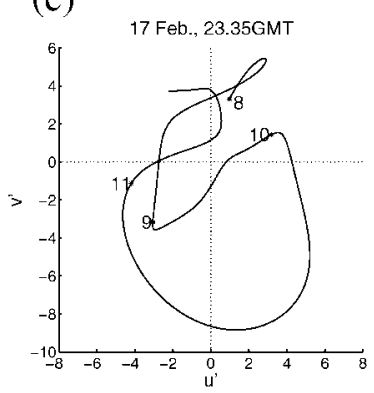

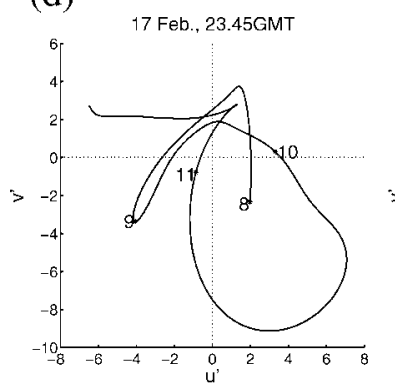

(e)

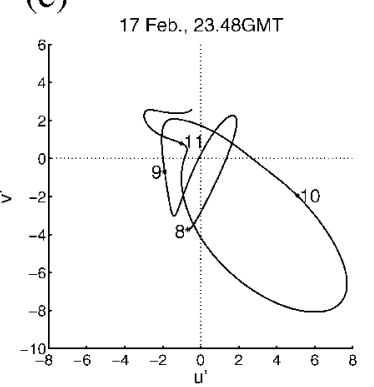

FIG. 14. Perturbation hodographs of the first five dropsondes (with good wind data) released from the G-IV. (Perturbation velocity is in $\mathrm{m} \mathrm{s}^{-1}$, and the vertical locations of the points on the hodograph are marked in $\mathrm{km}$.) Also, the relative locations of these dropsondes along the G-IV flight leg are described in Table 2.

Fig. 7a. Nonetheless, the dropsondes do have high vertical resolution, and hodograph techniques (e.g., Guest et al. 2000 and references therein) can be utilized to identify the presence of an inertia-gravity wave and its characteristics. However, given the limited stratospheric data from the dropsondes, and the inaccuracies of the modeled flow mentioned in the previous sections, it is overly ambitious to compare quantitative details of the observed and modeled inertia-gravity waves. Nevertheless, a qualitative comparison between the model and the derived wave parameters is useful for assessing the model's performance in producing realistic results.

The 13 dropsondes with complete wind measurements in the lower stratosphere are analyzed for gravity waves using the technique described by Plougonven et al. (2003). The vertical profiles of horizontal velocity from the dropsondes are separated into slowly varying background profiles and perturbation profiles (that con-

TABLE 2. Summary of wave characteristics derived from the hodograph method: sonde number, release time (UTC 17 Feb 2001), horizontal location of profile in Fig. $2 b(\mathrm{~km})$, vertical wavelength $\left(\lambda_{z}\right)$, and horizontal wavelength $\left(\lambda_{H}\right)$.

\begin{tabular}{ccccc}
\hline \hline Sonde & Time & Location & $\lambda_{z}(\mathrm{~km})$ & $\lambda_{H}(\mathrm{~km})$ \\
\hline 1 & 2326 & 0 & $1.4-1.8$ & $70-110$ \\
2 & 2331 & 55 & $1.3-1.5$ & $105-120$ \\
3 & 2335 & 110 & $1.0-1.4$ & $110-235$ \\
4 & 2345 & 220 & $1.2-2.1$ & $175-310$ \\
5 & 2348 & 260 & $2.2-2.3$ & $105-110$ \\
\hline
\end{tabular}

tain vertical scales between $500 \mathrm{~m}$ and $3.5 \mathrm{~km}$ ) using the filter described by Scavuzzo et al. (1998). These perturbation velocity profiles are used to construct perturbation hodographs. As described in previous studies (e.g., Guest et al. 2000; Plougonven et al. 2003), linear theory of gravity waves in a uniform background flow predicts that one vertical wavelength of an inertia-gravity wave traces an elliptical (perturbation) hodograph, which rotates anticyclonically for an upward-propagating wave and cyclonically for a downward-propagating wave. The orientation of the major axis of the ellipse is aligned with the horizontal wave vector of the inertiagravity wave, and the ratio of the major and minor axes of the ellipse is proportional to the wave frequency. Thus, as the vertical wavelength can be readily obtained from the sounding, the dispersion relation can be used to determine the remaining wave characteristics. This technique has limitations in conditions with strong background wind shear and is only appropriate for a part of the wave spectrum (the low-frequency, long-wave limit). See Plougonven et al. (2003) for the specifics of the technique and details of the limitations.

The hodograph technique is applied above $8 \mathrm{~km}$ to those dropsondes with good wind data (above $8 \mathrm{~km}$ ) shown in Fig. 2b. Of these 13 sondes, only the first 5 show clear evidence of anticyclonically rotating hodographs. These hodographs are shown in Fig. 14, and the characteristics inferred from these hodographs are summarized in Table 2. As can be seen from Table 2, these 
five sondes provide estimates of horizontal and vertical wavelengths that are similar to those determined from the numerical simulations. However, the estimates of vertical wavelengths from the sondes are generally between 0 and $1.5 \mathrm{~km}$ smaller than those in the model. The range of horizontal wavelengths surround the modeled wavelength of $180 \mathrm{~km}$. However, the limited depth of the stratosphere observed by the dropsondes, means that only one or two vertical wavelengths are sampled, which adds some uncertainty to the analysis.

Figure 14 shows that between sondes 1 and 5, the orientation of the wave vector undergoes a transition from pointing to the southwest (or northeast) (sonde 1) to pointing to the northwest (or southeast) (sonde 5). In the model, the wave vector points strictly to the southwest. Sondes 1 and 2 show a wave vector orientation that is consistent with the model, whereas sondes 3-5 show an inconsistent orientation. As seen in Fig. 2b, this change in orientation in the wave vector also coincides with the sondes that passed through more intense wind shear. There are at least two important difficulties in applying the hodograph method in regions of strong shear. First, Hines (1989) argues that the orientation of the hodograph-derived wave vector can be skewed toward the shear vector by vertical advection of the background wind shear. Indeed, the wave vector orientation of sonde 5 is aligned with the background shear. Second, in regions of stronger shear, the filtering applied to the wind profiles is less effective. Subsequently, signals of the strong shear can be unintentionally incorporated into the perturbation hodograph, aligning the major axis of the hodograph with the shear vector. Therefore, because of these limitations, the apparent inconsistencies in the wave vector orientations may be due solely to the limitations of the technique in regions of strong shear.

The horizontal wavelengths determined using the hodograph method and those inferred from the CHM simulation show good agreement. Also, those sondes with strong wave signatures are in the same region relative to the jet as the waves in the model. However, given the limitations of the hodograph technique in its application to this case, it is difficult to make definitive conclusions about the consistency between the observed and modeled waves. Certainly, there appear to be no significant inconsistencies.

\section{Summary and conclusions}

An intense jet stream/upper-level front was observed on 18 February 2001 during SCATCAT. These observations were 17 closely spaced dropsondes $(\sim 40 \mathrm{~km}$ separation) released from NOAA's G-IV weather reconnaissance aircraft above the jet/front system. Following the dropsonde deployment, the G-IV completed stacked flight legs in the strong vertical shear region above the jet core. While completing these legs, the G-IV encountered clear-air turbulence in regions that were identified as possible regions of gravity wave activity.
Analysis of the dropsonde observations showed that the maximum wind speed of the jet exceeded $100 \mathrm{~m} \mathrm{~s}^{-1}$, with very strong wind shear above and below the jet core. Associated with this jet was a strong upper-level front, and deep tropopause fold, elucidated by a COAMPS forecast. The COAMPS forecast compared qualitatively well with the observations and was used as the initial conditions and boundary conditions for a finer-scale multiply nested model (CHM).

Using nesting, the CHM simulation resolved the jet/ front system on a grid that had horizontal grid spacing of $3 \mathrm{~km}$ and vertical grid spacing of $100 \mathrm{~m}$. As the upper front intensified, inertia-gravity waves intensified also and propagated vertically through the strong negative (speed) shear region above and to the anticyclonic side of the jet core. These waves had a horizontal wavelength of about $180 \mathrm{~km}$ and a vertical wavelength of about $2.5 \mathrm{~km}$, and were shown to be insensitive to model resolution.

In the region of the jet, the Richardson number was generally low $(\mathrm{Ri} \sim 2)$, and as the inertia-gravity waves propagated through the strong shear zone, the wave perturbations significantly modified the local Richardson number. Subsequently, along the phase lines of the gravity waves there appeared bands of increased and reduced $(\mathrm{Ri}<1)$ Richardson numbers. These bands of $\mathrm{Ri}<1$ were regions of possible Kelvin-Helmholtz instability. Further nesting (with horizontal and vertical grid spacings of $1 \mathrm{~km}$ and $50 \mathrm{~m}$, respectively) showed that localized volumes of enhanced resolved and subgrid turbulent kinetic energy formed in the bands of reduced Richardson numbers. This enhanced turbulence was due to the inertia-gravity waves and it is proposed that such a mechanism contributed to the turbulence encountered by the G-IV.

Even in the highest-resolution domain, there was no convective overturning on the scale of the inertia-gravity wave, and therefore the waves were able to propagate through the region of Kelvin-Helmholtz instability without breaking per se. However, from this study it is difficult to determine what effect the instability has on the properties of the propagating gravity wave, once it has propagated through the shear layer. This will be considered in future research.

The hodograph technique was used to analyze the dropsondes for inertia-gravity waves. This analysis did show the presence of an inertia-gravity wave above the jet, whose characteristics displayed some consistency with those of the simulated waves. However, because of the limited stratospheric data, and the imperfections of the hodograph method in regions of strong wind shear, the comparisons with the simulation were limited.

In conclusion, this study has examined inertia-gravity waves generated by a jet stream-upper-level frontal system that propagated through the strongly sheared flow above the jet, and subsequently generated CAT. Nevertheless, this study has investigated inertia-gravity wave and turbulence generation in only one part of a 
baroclinic wave: where inertia-gravity waves exist in the northwesterly jet stream flow toward a trough, with phase lines that are closely aligned with the flow. This flow regime was also studied by O'Sullivan and Dunkerton (1995). Another regime was examined by Zhang (2004): the southwesterly jet stream flow toward a ridge, which generated gravity waves with phase lines perpendicular to the mean flow. Idealized studies (e.g., Zhang 2004) can be used to examine the difference between these flow regimes, the mechanisms controlling the wave source, and the details of the wave propagation; such idealized studies are clearer and less complicated than real cases, such as the one considered here. Idealized studies of these different flow regimes and their relationship to clear-air turbulence is a topic of continuing research.

Acknowledgments. This research was funded in part by the Federal Aviation Administration's (FAA) Aviation Weather Research Program. The views expressed are those of the authors and do not necessarily represent the official policy or position of the FAA. COAMPS is a trademark of the Naval Research Laboratory. Special thanks go to the NOAA Aircraft Operations Center for providing the NOAA G-IV, and to Cecilia Girz for her efforts in organizing SCATCAT. Thank you also to Charles Martin for providing the software that assisted in the dropsonde analysis. This study has benefited from the authors' conversations with Terry Clark, Steve Koch, Michael Reeder, and Fuqing Zhang. Also, thanks to Fuqing Zhang and three anonymous reviewers for providing comments on an earlier version of the manuscript.

\section{REFERENCES}

Bougeault, P., 1983: A non-reflective upper boundary condition for limited-height hydrostatic models. Mon. Wea. Rev., 111, 420429.

Clark, T. L., 1977: A small-scale dynamic model using a terrainfollowing coordinate transformation. J. Comput. Phys., 24, 186215.

___ and W. D. Hall, 1991: Multi-domain simulations of the time dependent Navier-Stokes equations: Benchmark error analysis of some nesting procedures. J. Comput. Phys., 92, 456-481.

—_ — - and J. L. Coen, 1996: Source code documentation for the Clark-Hall cloud-scale model: Code version G3CH01. NCAR Tech. Note NCAR/TN-426+STR, 137 pp.

,,-- R. M. Kerr, D. Middleton, L. Radke, F. M. Ralph, P. J. Neiman, and D. Levinson, 2000: Origins of aircraft-damaging clear-air turbulence during the 9 December 1992 Colorado downslope windstorm: Numerical simulations and comparison with observations. J. Atmos. Sci., 57, 1105-1131.

Davies, H. C., 1976: A lateral boundary formulation for multi-level prediction models. Quart. J. Roy. Meteor. Soc., 102, 405-418.

Deardorff, J. W., 1980: Stratocumulus-capped mixed layers derived from a three-dimensional model. Bound.-Layer Meteor., 18, 495-527.

Einaudi, F., and D. P. Lalas, 1975: Wave-induced instabilities in an atmosphere near saturation. J. Atmos. Sci., 32, 536-547.

Fritts, D. C., and M. J. Alexander, 2003: Gravity wave dynamics and effects in the middle atmosphere. Rev. Geophys., 41, 1003, doi:10.1029/2001RG000106.
Gill, A. E., 1982: Atmosphere-Ocean Dynamics. Academic Press, $622 \mathrm{pp}$.

Griffiths, M., and M. J. Reeder, 1996: Stratospheric inertia-gravity waves generated in a numerical model of frontogenesis. I: Model solutions. Quart. J. Roy. Meteor. Soc., 122, 1153-1174.

Guest, F. M., M. J. Reeder, C. J. Marks, and D. J. Karoly, 2000: Inertia-gravity waves observed in the lower stratosphere over Macquarie Island. J. Atmos. Sci., 57, 737-752.

Hines, C. O., 1989: Tropopausal mountain waves over Arecibo: A case study. J. Atmos. Sci., 46, 476-488.

Hodur, R. M., 1997: The Naval Research Laboratory's Coupled Ocean/Atmosphere Mesoscale Prediction System (COAMPS). Mon. Wea. Rev., 125, 1414-1430.

_- and J. D. Doyle, 1999: The coupled ocean/atmosphere mesoscale model prediction system (COAMPS). Coastal Ocean Prediction, C. N. K. Mooers, Ed., Coastal and Estuarine Studies Series, Vol. 56, Amer. Geophys. Union, 125-155.

Keller, J. L., 1990: Clear air turbulence as a response to meso- and synoptic-scale dynamic processes. Mon. Wea. Rev., 118, 22282242.

Kennedy, P. J., and M. A. Shapiro, 1980: Further encounters with clear air turbulence in research aircraft. J. Atmos. Sci., 37, 986993.

Kessler, E., 1969: On the Distribution and Continuity of Water Substance in Atmospheric Circulations. Meteor. Monogr., No. 32, Amer. Meteor. Soc., 84 pp.

Klemp, J. B., and D. R. Durran, 1983: An upper boundary condition permitting internal gravity wave radiation in numerical mesoscale models. Mon. Wea. Rev., 111, 430-444.

Knox, J. A., 1997: Possible mechanisms of clear-air turbulence in strongly anticyclonic flows. Mon. Wea. Rev., 125, 1251-1259.

Koch, S. E., M. A. Shapiro, B. Jamison, E. Tollerud, and T. Smith, 2003: Generation of turbulence within an upper-tropospheric front. Preprints, 10th Conf. on Mesoscale Processes, Portland, OR, Amer. Meteor. Soc., P2.24.

Lilly, D. K., 1962: On the numerical simulation of buoyant convection. Tellus, 14, 145-172.

Lindzen, R. S., and M. Fox-Rabinovitz, 1989: Consistent vertical and horizontal resolution. Mon. Wea. Rev., 117, 2575-2583.

Mancuso, R. L., and R. M. Endlich, 1966: Clear air turbulence frequency as a function of wind shear and deformation. Mon. Wea. Rev., 94, 581-585.

O'Sullivan, D., and T. J. Dunkerton, 1995: Generation of inertiagravity waves in a simulated life cycle of baroclinic instability. J. Atmos. Sci., 52, 3695-3716.

Pavelin, E., J. A., Whiteway, and G. Vaughan, 2001: Observations of gravity wave generation and breaking in the lowermost stratosphere. J. Geophys. Res., 106, 5173-5179.

,,-- R. Busen, and J. Hacker, 2002: Airborne observations of turbulence mixing and gravity waves in the tropopause region. J. Geophys. Res., 107, 4084, doi:10.1029/2001JD000775.

Pecnick, M. J., and D. Keyser, 1989: The effect of spatial resolution on the simulation of upper-tropospheric frontogenesis using a sigma-coordinate primitive equation model. Meteor. Atmos. Phys., 40, 137-149.

Persson, P. O. G., and T. T. Warner, 1991: Model generation of spurious gravity waves due to inconsistency of the vertical and horizontal resolution. Mon. Wea. Rev., 119, 917-935.

Plougonven, R., H. Teitelbaum, and V. Zeitlin, 2003: Inertia gravity wave generation by the tropospheric midlatitude jet as given by the Fronts and Atlantic Storm-Track Experiment radio soundings. J. Geophys. Res., 108, 4686, doi:10.1029/2003JD003535.

Powers, J. G., and R. J. Reed, 1993: Numerical model simulation of the large-amplitude mesoscale gravity-wave event of 15 December 1987 in the central United States. Mon. Wea. Rev., 121, 2285-2308.

Reeder, M. J., and M. Griffiths, 1996: Stratospheric inertia-gravity waves generated in a numerical model of frontogenesis. II: Wave sources, generation mechanisms, and momentum fluxes. Quart. J. Roy. Meteor. Soc., 122, 1175-1195. 
Scavuzzo, C. M., M. A. Lamfri, H. Teitelbaum, and F. Lott, 1998: A study of the low-frequency inertio-gravity waves observed during the Pyrenees Experiment. J. Geophys. Res., 103, 1747-1758.

Shapiro, M. A., 1980: Turbulent mixing within tropopause folds as a mechanism for the exchange of chemical constituents between the stratosphere and troposphere. J. Atmos. Sci., 37, 994-1004.

Smagorinsky, J., 1963: General circulation experiments with the primitive equations. I. The basic experiment. Mon. Wea. Rev., 91, 99-164.

Snyder, C., W. C. Skamarock, and R. Rotunno, 1993: Frontal dy- namics near and following frontal collapse. J. Atmos. Sci., 50, 3194-3211.

Uccellini, L. W., and S. E. Koch, 1987: The synoptic setting and possible energy sources for mesoscale wave disturbances. Mon. Wea. Rev., 115, 721-729.

Zhang, F., 2004: Generation of mesoscale gravity waves in the uppertropospheric jet-front systems. J. Atmos. Sci., 61, 440-457.

- S. E. Koch, C. A. Davis, and M. L. Kaplan, 2001: Wavelet analysis and the governing dynamics of a large-amplitude gravity wave event along the east coast of the United States. Quart. J. Roy. Meteor. Soc., 127, 2209-2245. 